\title{
Optimization of physicochemical parameters in the biofabrication of gold nanoparticles using marine macroalgae Padina tetrastromatica and its catalytic efficacy in the degradation of organic dyes
}

\author{
K. F. Princy ${ }^{1} \cdot$ Anu Gopinath ${ }^{2}$
}

Received: 27 June 2018 / Accepted: 17 August 2018 / Published online: 3 September 2018

(c) The Author(s) 2018

\begin{abstract}
Green synthesis of metallic nanoparticles by means of renewable bioresources has emerged as a new trend in current nanotechnology research with improved environmental safety. In the current study, monodispersed gold nanoparticles (AuNPs) with excellent stability were prepared in a completely green and cost effective manner using aqueous extract of marine macroalgae-Padina tetrastromatica. The influence of reaction conditions such as the quantity of seaweed extract, temperature, precursor metal ion concentration, reaction time and $\mathrm{pH}$ on the biosynthesis of nanoparticle was evaluated spectroscopically and also with the help of high resolution transmission electron microscopy (HR-TEM). These physicochemical parameters not only affected the rate of formation but also the size and morphology of resultant nanoparticles. Optimum conditions resulted in the generation of nearly spherical AuNPs having an average particle size of $11.4 \mathrm{~nm}$. The high crystallinity of the biogenic AuNPs was confirmed from characteristic diffraction peaks in XRD profile, clear lattice fringes in the HR-TEM image and bright circular spots in the SAED pattern. The presence of metallic gold was evidenced from EDAX profile. FTIR study revealed the role of secondary metabolites in the bioreduction as well as stabilization of AuNPs. The study also highlights the spectroscopic investigation on the catalytic efficacy of the biosynthesized AuNPs in the reduction reactions of hazardous organic dyes, eosin yellow and Congo red using sodium borohydride, which have a pseudo-first order kinetics. Thus, the biosynthesized metal nanoparticles using renewable marine resources like seaweeds act as promising materials for the application in environmental protection.
\end{abstract}

\section{Graphical abstract}

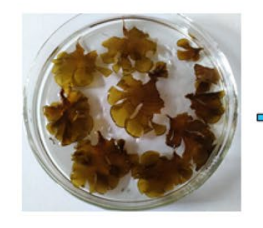

Padina Tetrastromatica

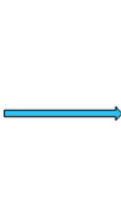

Aqueous Extract
Chloroauric acid

Optimum conditions

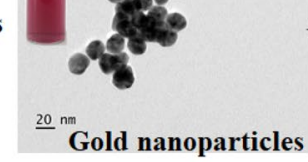

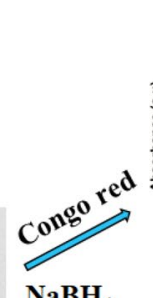

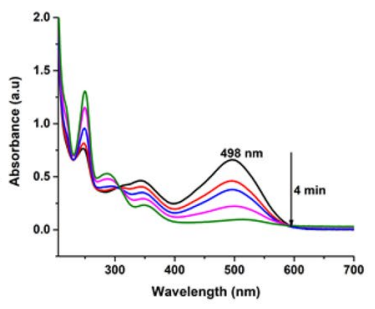

$\mathrm{NaBH}_{4}$
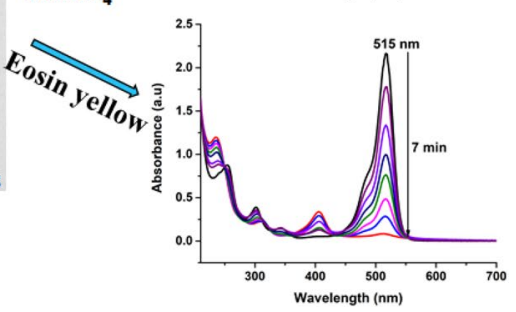

Extended author information available on the last page of the article 
Keywords Gold nanoparticles · Padina tetrastromatica $\cdot$ Green synthesis · Process optimization · Catalytic efficacy $\cdot$ Dye degradation

\section{Introduction}

Noble metal nanoparticles are gaining significant attention nowadays due to their attractive optoelectronic properties as against their bulk counterparts. Among these nanoparticles, the gold nanoparticles are renowned for its promising applications in medicine, catalysis, optics, electronics and sensing [1-4]. Several physical and chemical synthetic strategies are available for the preparation of AuNPs. But they are often costly and employ noxious chemicals that are potentially hazardous to the environment [5]. So there is an emerging interest associated with the development of cheap, non- toxic and environmentally benign processes for nanosynthesis.

Recently, biosynthetic procedures employing microbes and plant extracts have aroused as a facile and feasible substitute for commonly used physical and chemical methodologies due to its simplicity, ecofriendliness and cost effective nature [6]. Nevertheless, plant mediated nanosynthesis are more beneficial over microbe assisted procedures in the case of easiness, fast rate of synthesis, abundant availability of resources and ecofriendliness. Moreover it eradicates the complicated procedure of preserving microbial cultures and could also be stretched to bulk-scale production. Previous literature revealed that terrestrial plants have been extensively utilized for the preparation of metal nanoparticles [7-12] and only a limited number of reports on nanogold synthesis using renewable marine resources like marine macroalgae (seaweeds) $[13,14]$. Due to the richness of bioactive metabolites, marine macroalgae are promising source for both industrial and biotechnological applications.

Herein, we explored the utility of aqueous Padina tetrastromatica extract for the fabrication of AuNPs. Padina tetrastromatica belongs to the family of Dictyotaceae, is a marine brown algae having plenty of phytochemicals like flavonoids, steroids, saponins, tannins, phenols and proteins [15]. The algal extract itself performed as reductant and stabilizer. Since no toxic chemicals used in the synthetic protocol, it is completely a green chemistry process. Further, the size, shape and morphological characteristics of the nanoparticles can be controlled and improved by altering the reaction conditions like quantity of extract, temperature, precursor metal ion concentration, $\mathrm{pH}$ and incubation time [16]. So we have carried out a detailed investigation on the effect of these physicochemical parameters on the formation of AuNPs and also demonstrated spectroscopically the catalytic efficacy of the optimized AuNPs for the degradation of hazardous dyes Congo red and eosin yellow by sodium borohydride.

\section{Materials and methods}

Chloroauric acid of purity $99.9 \%$ was obtained from Sigma-Aldrich. Congo red, eosin yellow and sodium borohydride were supplied by Merck India Ltd. Milli Q water is used to prepare all experimental solutions.

\section{Preparation of seaweeds extract}

The seaweed Padina tetrastromatica was collected manually from the coast of Thirumullavaram $\left(8^{\circ} 53^{\prime} 38^{\prime \prime} \mathrm{N}\right.$; $76^{\circ} 33^{\prime} 14^{\prime \prime}$ E), Kollam district of Kerala and washed thoroughly in seawater. They were again washed several times in Milli Q water and dried in air. $10 \mathrm{~g}$ of the chopped algae were mixed with $100 \mathrm{~mL}$ of sterile Milli Q water and kept in a water bath at $60{ }^{\circ} \mathrm{C}$ for $20 \mathrm{~min}$ [17]. It was then allowed to cool and strained by means of Whatman No. 1 filter paper. The resultant filtrate was used for biosynthesis.

\section{Optimization of reaction parameters for the biosynthesis of AuNPs}

\section{Quantity of seaweed extract (SWE)}

Volume of SWE required for the biosynthesis of AuNPs was optimized by adding varying quantity of extract $(1 \mathrm{~mL}, 2 \mathrm{~mL}, 3 \mathrm{~mL}, 4 \mathrm{~mL}, 5 \mathrm{~mL}, 8 \mathrm{~mL}$ and $10 \mathrm{~mL}$ ) to $10 \mathrm{~mL}$ of $1 \mathrm{mM}$ Chloroauric acid solution at room temperature. The reaction mixtures were mixed thoroughly and incubated in dark.

\section{Temperature}

To analyse the influence of temperature on the biosynthesis of AuNPs, the reaction mixtures were maintained at three different temperatures namely, room temperature (RT), 60 and $90{ }^{\circ} \mathrm{C}$ till the completion of the reaction without changing the $\mathrm{pH}$.

\section{Metal ion concentration}

To evaluate the impact of concentration of Chloroauric acid on AuNPs formation, $10 \mathrm{~mL}$ of four different concentrations of $\mathrm{HAuCl}_{4}(0.1 \mathrm{mM}, 0.5 \mathrm{mM}, 1 \mathrm{mM}$ and $2 \mathrm{mM})$ 
was mixed with $2 \mathrm{~mL}$ of SWE at room temperature without altering the $\mathrm{pH}$.

\section{$\mathrm{pH}$}

The influence of $\mathrm{pH}$ on the formation of AuNPs was examined by keeping the $\mathrm{pH}$ of the reaction medium (which is obtained by adding $10 \mathrm{~mL}$ of $1 \mathrm{mM}$ Chloroauric acid to $2 \mathrm{~mL}$ of SWE) at $3.2,7$ and 10 , respectively at room temperature.

\section{Reaction time}

To optimize reaction time, the biosynthesis of AuNPs was monitored periodically in a UV-visible spectrophotometer. The reaction mixture comprising $10 \mathrm{~mL}$ of $1 \mathrm{mM}$ Chloric acid and $2 \mathrm{~mL}$ of SWE at RT was monitored as a function of reaction time from $0 \mathrm{~min}$ to $48 \mathrm{~h}$.

\section{Characterization}

Optimization of reaction parameters for the biosynthesis of AuNPs was performed using Thermo scientific Evolution $201 \mathrm{UV}$-visible spectrophotometer in the wavelength range of 300-700 $\mathrm{nm}$. After $24 \mathrm{~h}$ of reaction, the biosynthesized AuNPs were purified by repeated centrifugation at $15,000 \mathrm{rpm}$ for $20 \mathrm{~min}$ at $4{ }^{\circ} \mathrm{C}$. The resultant precipitate was redispersed in sterile Milli Q water and freeze dried. The freeze dried AuNPs were then characterized using high resolution transmission electron microscopy (HR-TEM), Selected area electron diffraction (SAED), Energy dispersive X-ray analysis (EDAX), X-ray diffraction (XRD) and Fourier transform infrared spectroscopy (FTIR) techniques. FTIR measurements of freeze dried AuNPs and SWE were recorded using Perkin Elmer Spectrum 100 at the wavelength range of $4000-500 \mathrm{~cm}^{-1}$. XRD pattern was recorded by PANalytic X'PERT-PRO X-ray spectrometer by means of $\mathrm{Cu} \mathrm{K} \alpha$ radiation $(\lambda=0.1542 \mathrm{~nm})$ functioned at a voltage of $40 \mathrm{kV}$ and a current of $30 \mathrm{~mA}$. HR-TEM images, EDAX and SAED patterns have been acquired with Tecnai $\mathrm{G}^{2} 30$ transmission electron microscope.

\section{Catalytic activity}

The catalytic efficacy of the biosynthesized AuNPs at optimum conditions was exploited for the degradation of hazardous dyes eosin yellow and Congo red using $\mathrm{NaBH}_{4}$ by following the method of Gangula et al. [18], with slight modification. To $1.4 \mathrm{~mL}$ of water taken in a quartz cell, $0.3 \mathrm{~mL}$ of $2 \mathrm{mM}$ aqueous dye and $1 \mathrm{~mL}$ of $0.03 \mathrm{M}$ of recently made $\mathrm{NaBH}_{4}$ solutions were added. To this, $100 \mu \mathrm{L}$ of biogenic AuNPs ( $1 \mathrm{mg} / \mathrm{mL}$ ) was added and the periodic monitoring of the degradation reactions was carried spectroscopically at regular intervals. Control experiments were also executed without gold nanocatalyst. Kinetics of the degradation reactions were also investigated. Moreover, the degradation effectiveness of the AuNPs for each dye pollutant is estimated by means of the equation, $\%$ degradation $=\left\{\left(A_{0}-A_{t}\right) / A_{0}\right\} \times 100$, where $A_{0}$ and $A_{t}$ are the absorbance at 0 and $t$ minutes, respectively.

\section{Results and discussion}

The biotransformation of $\mathrm{Au}^{3+}$ ions to AuNPs during exposure to SWE was primarily evidenced from the colour variation of reaction medium from pale yellow to pink or purple owing to the excitation of surface plasmon resonance (SPR) in the AuNPs [19]. Further, optimization of reaction conditions like the quantity of SWE, temperature, precursor metal ion concentration, $\mathrm{pH}$ and reaction time was carried out using UV-visible spectroscopy and HR-TEM analysis.

\section{Effect of quantity of SWE on the biosynthesis of AuNPs}

The UV-visible spectra depicted in Fig. 1a-c, describes the impact of varying volumes of SWE at RT, 60 and $90{ }^{\circ} \mathrm{C}$, respectively, on the biosynthesis of AuNPs. From the spectra it is evident that at all the three temperatures, as the quantity of SWE is augmented from 1 to $2 \mathrm{~mL}$, the SPR band moved towards lower wavelength region signifying a decrease in particle dimension. Further rise in the extract volume resulted in broad SPR bands due to the agglomeration of the nanoparticles [20]. Moreover, photograph of AuNPs (Fig. 1d) at varying quantity of SWE revealed that after $2 \mathrm{~mL}$, the colour of AuNPs changes to purple and then to blue owing to the rise in particle size. Thus the volume of SWE played a crucial part in deciding the size distribution of AuNPs and $2 \mathrm{~mL}$ is found to be the optimum quantity of extract required for the biosynthesis.

\section{Influence of temperature on the green synthesis of AuNPs}

Figure 2a shows the absorption spectra of AuNPs formed with $2 \mathrm{~mL}$ of SWE at different temperatures. From the spectra it is clear that with the rise temperature from RT to $90{ }^{\circ} \mathrm{C}$, the absorption bands of AuNPs underwent a red shift from 532 to $544 \mathrm{~nm}$. This red shift is due to an increase in the particle size at high temperature owing to the agglomeration of particles [21], which was further confirmed from the digital photographs (Fig. 2b) and HR-TEM images (Fig. 2c) of AuNPs at various temperatures. At room temperature, monodispersed particles of almost spherical shape were observed. Thus temperature performed a significant role 

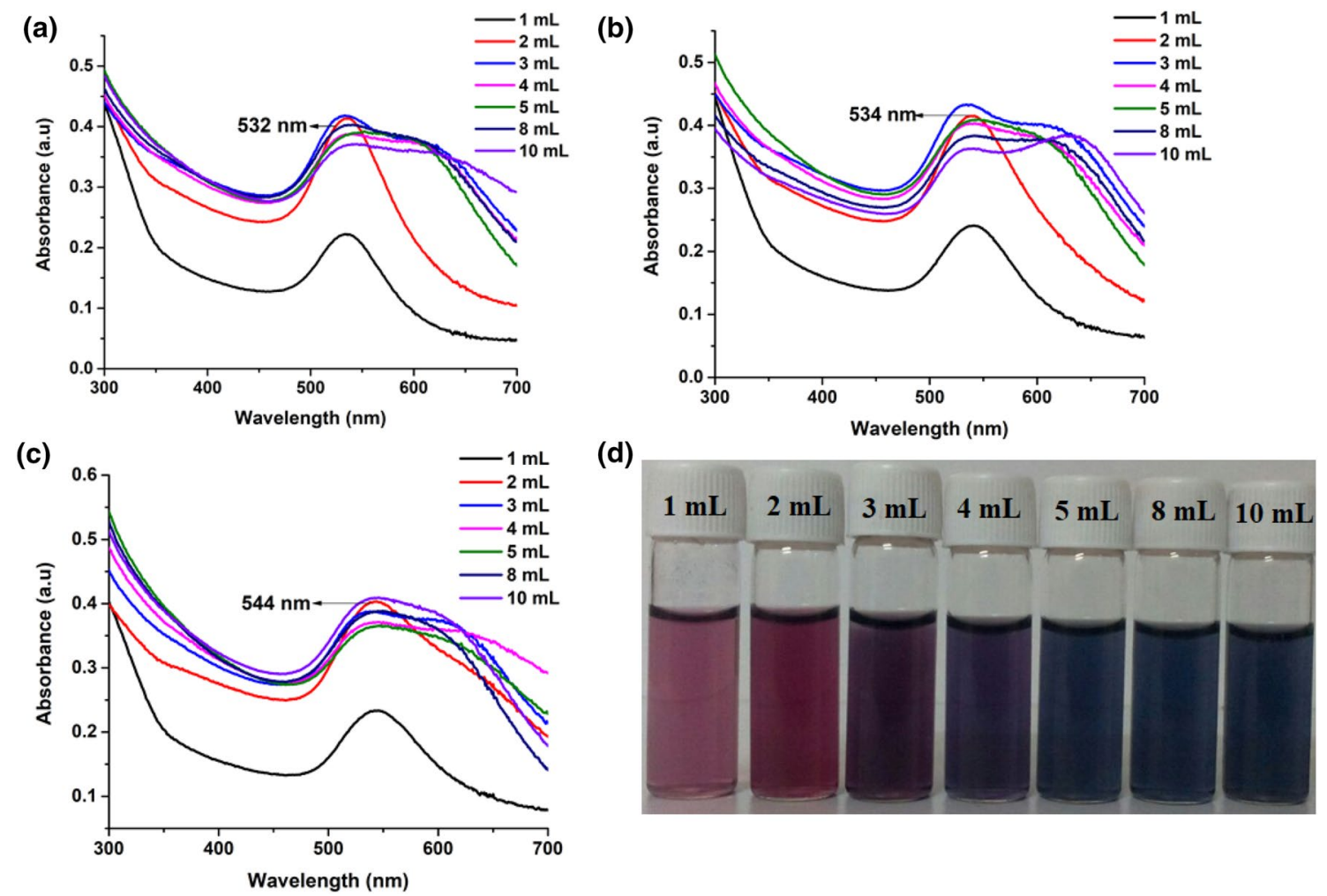

Fig. 1 The UV-visible absorption spectra of AuNPs at a RT b $60{ }^{\circ} \mathrm{C} \mathrm{c} 90{ }^{\circ} \mathrm{C}$ and $\mathbf{d}$ digital images of AuNPs formed with varying volumes of SWE at RT

(a)

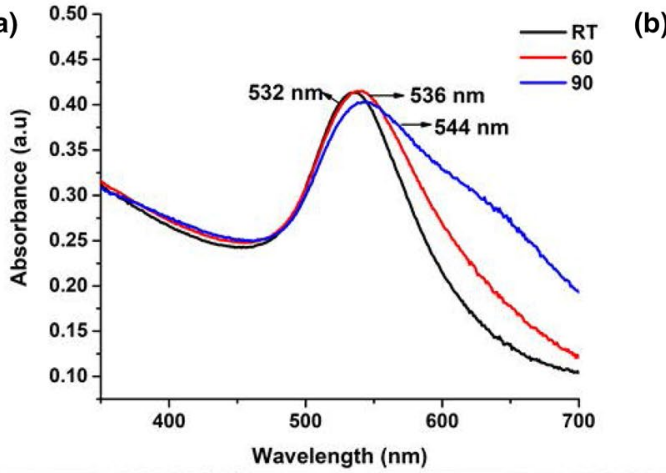

(b)

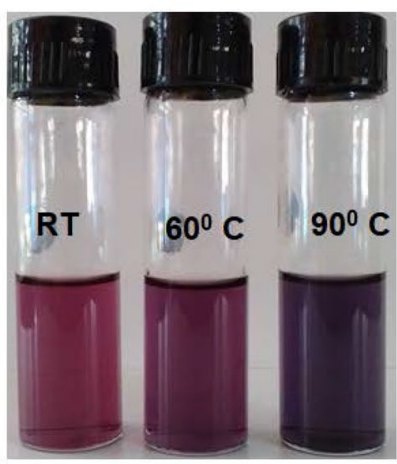

(c)

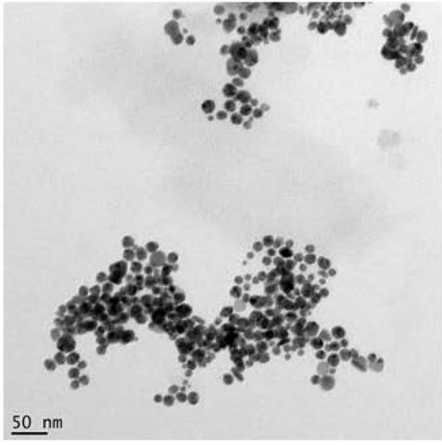

RT (d)

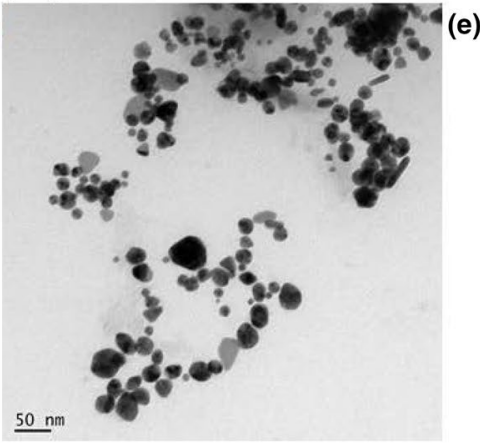

$60^{\circ} \mathrm{C}$

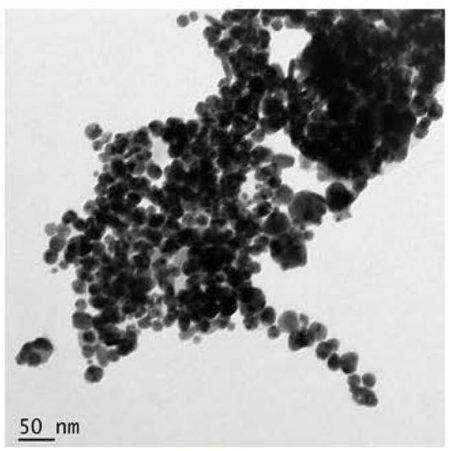

$90^{\circ} \mathrm{C}$

Fig. 2 a The UV-visible absorption spectra of AuNPs formed with $2 \mathrm{~mL}$ of SWE at various temperatures, b digital images of AuNPs formed with $2 \mathrm{~mL}$ of SWE at various temperatures and $\mathbf{c}-\mathbf{e}$ HR-TEM images of AuNPs formed with $2 \mathrm{~mL}$ of SWE at various temperatures 
in determining the morphological characteristics of the nanoparticles.

\section{Effect of concentration of $\mathrm{HAuCl}_{4}$ solution on the biosynthesis of AuNPs}

The absorption spectra and the corresponding colour changes of the AuNPs generated at various concentration of Chloroauric acid have been presented in Fig. 3a, b. From the spectra it is clear that, at very low concentration of Chloroauric acid $(0.1 \mathrm{mM})$, no characteristic SPR peak of AuNPs was perceived. But when the concentration increases to $0.5 \mathrm{mM}$, a broad band at $536 \mathrm{~nm}$ was witnessed and the spectra underwent a blue shift to $532 \mathrm{~nm}$ with increase in the concentration to $1 \mathrm{mM}$. Further increase in the $\mathrm{HAuCl}_{4}$ concentration resulted in a shift towards longer wavelength $(541 \mathrm{~nm})$ due to the increase in particle size. The HR-TEM images (Fig. 3c-e) showed a good agreement with the corresponding UV-visible absorption spectra. By considering these results, it could be finalised that, the optimum concentration of Chloroauric acid for the preparation of AuNPs using Padina tetrastromatica is $1 \mathrm{mM}$. Similar interpretations were also stated by Ghosh et al. [22].

\section{Influence of pH}

The $\mathrm{pH}$ of the reaction mixture obtained by adding $2 \mathrm{~mL}$ of SWE to $10 \mathrm{~mL}$ of $1 \mathrm{mM}$ Chloroauric acid was observed to be 3.2. The UV-visible spectra (Fig. 4a) and the corresponding digital photographs (Fig. 4b) and HR-TEM images (Fig. 4c-e) revealed that more spherical and homogeneous AuNPs were formed at $\mathrm{pH} 3.2$ which is consistent with earlier reports [23]. Moreover, by altering the $\mathrm{pH}$ to 7 or to 10, the AuNPs formed became polydispersed. Therefore $\mathrm{pH}$ of the reaction mixture itself is the optimum $\mathrm{pH}$ for this biosynthesis.

\section{Influence of reaction time}

The bioreduction of $\mathrm{Au}^{3+}$ ions to $\mathrm{Au}^{0}$ mediated by Padina tetrastromatica extract at optimum conditions was examined spectroscopically at different reaction time and the stacked spectra is displayed in Fig. 5a. The biosynthesis of AuNPs started within 5 min which showed an SPR band at $540 \mathrm{~nm}$. As the reaction continues, the intensity of this band increases together with a blue shift to $532 \mathrm{~nm}$ attributed to the creation of small sized spherical nanoparticles. The biosynthesis was found to be completed within

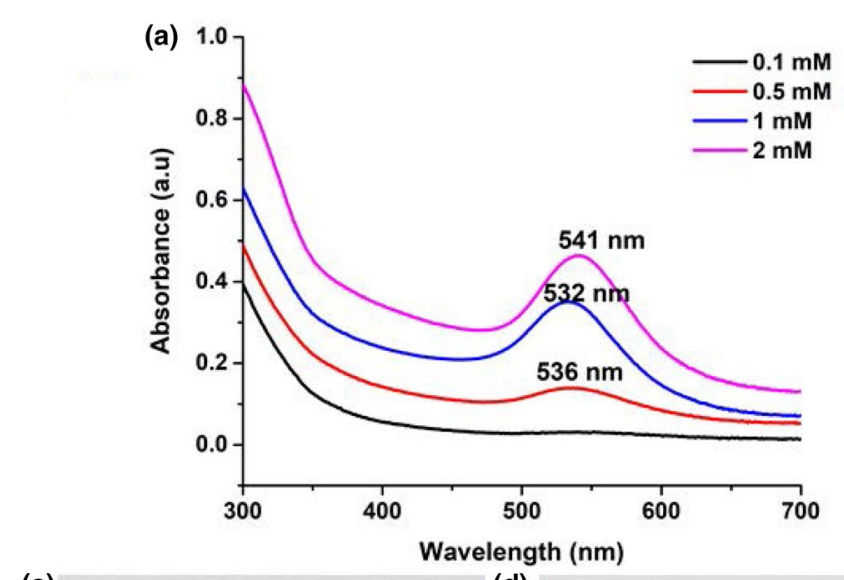

(c)

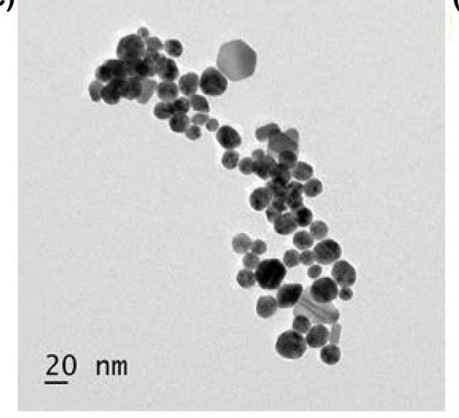

$0.5 \mathrm{mM}$ (d)

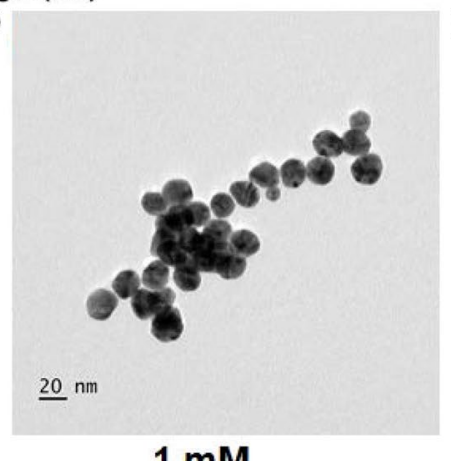

$1 \mathrm{mM}$ (b)

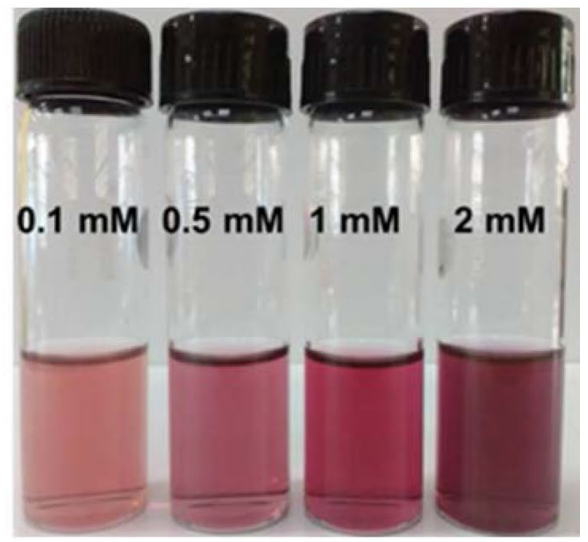

(e)

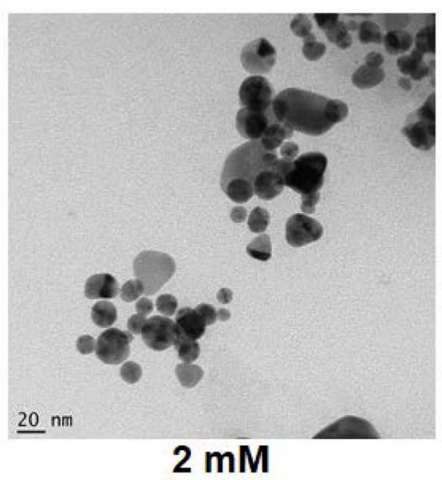

Fig. 3 a The UV-visible absorption spectra of AuNPs formed at varying $\mathrm{HAuCl}_{4}$ concentrations b digital photograph and $\mathbf{c}-\mathbf{e} \mathrm{HR}-\mathrm{TEM}$ images of AuNPs formed with $2 \mathrm{~mL}$ of SWE at various $\mathrm{HAuCl}_{4}$ concentrations 

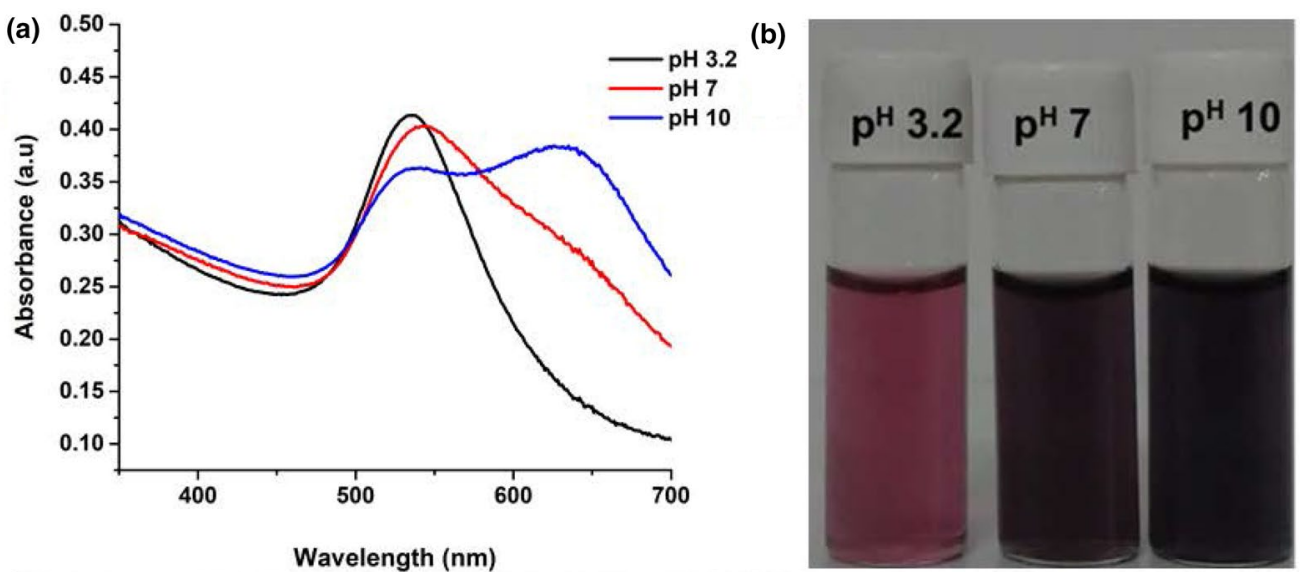

(c)

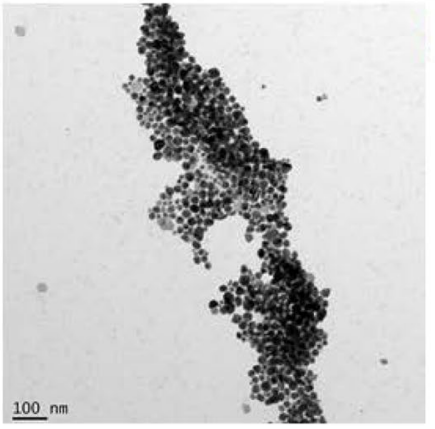

(d)

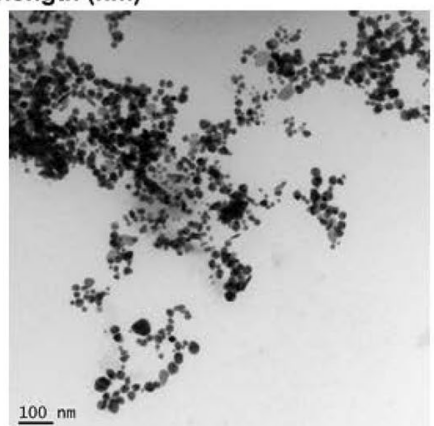

(e)

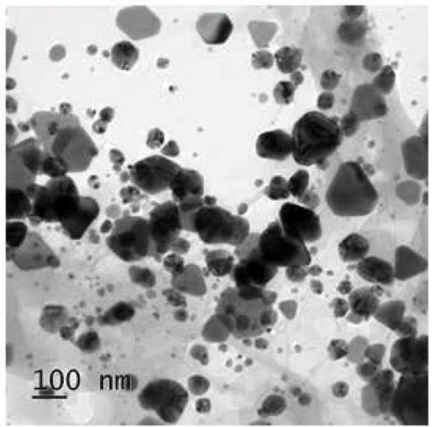

Fig. 4 a The UV-visible absorption spectra of AuNPs at different $\mathrm{pH}$ ranges $\mathbf{b}$ digital images and $\mathbf{c}-\mathbf{e}$ HR-TEM images of AuNPs at various pH ranges
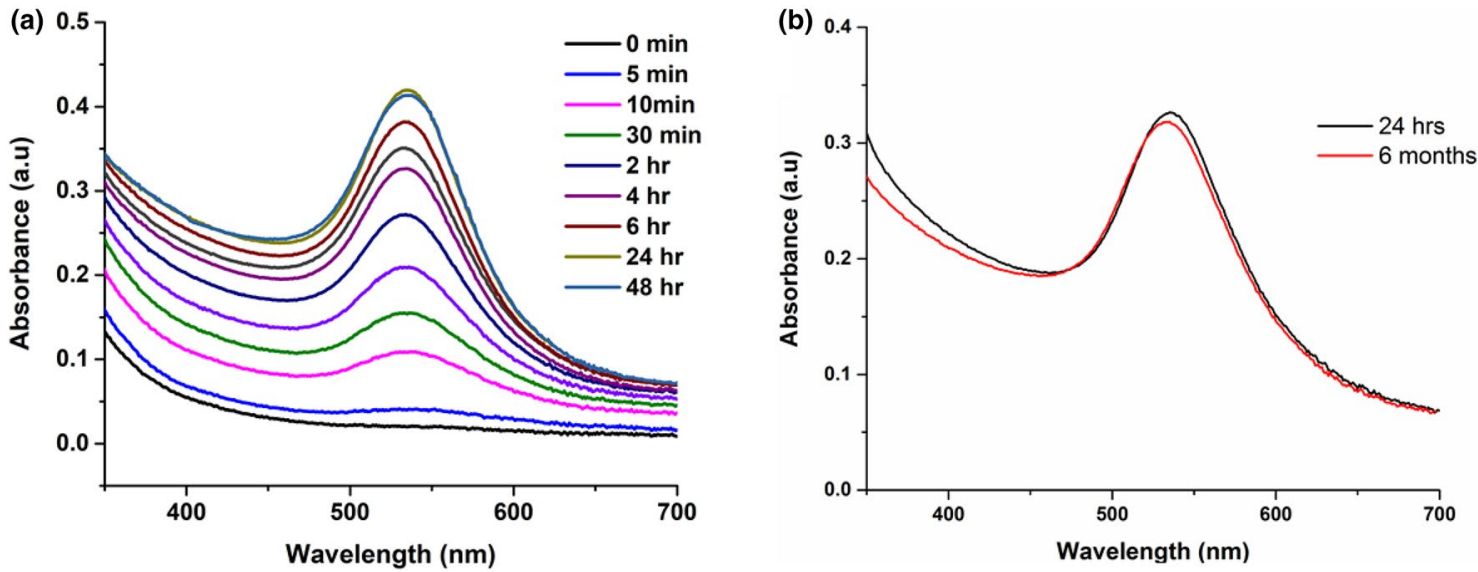

Fig. 5 a UV-visible absorption spectra of AuNPs at different reaction time and $\mathbf{b}$ after 6 months

$24 \mathrm{~h}$ and no further rise in the intensity of SPR band was detected. Also, there was no appreciable change observed in the colour and UV-visible spectrum of the biosynthesized AuNPs even after 6 months, indicating the presence of well stabilized nanoparticles in the solution (Fig. 5b).

\section{Characterization studies of AuNPs at optimum conditions}

HR-TEM images at various magnifications (Fig. 6a-c) revealed that at optimum conditions, the biosynthesized AuNPs have almost spherical shape with an average size of 
(a)

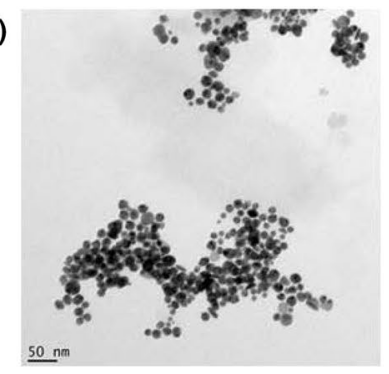

(b)

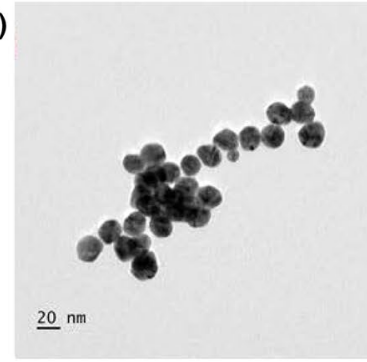

(c)

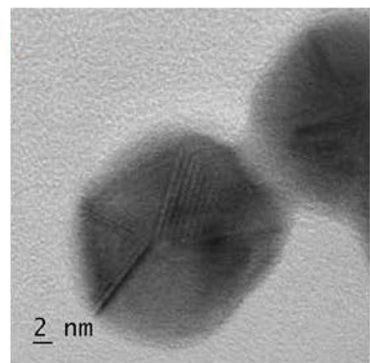

(d)

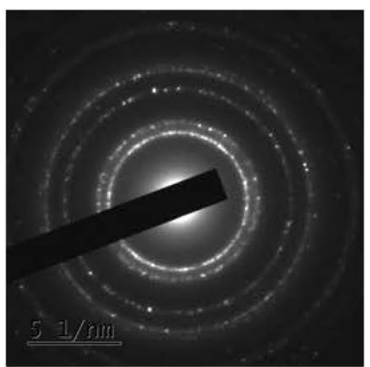

(e)

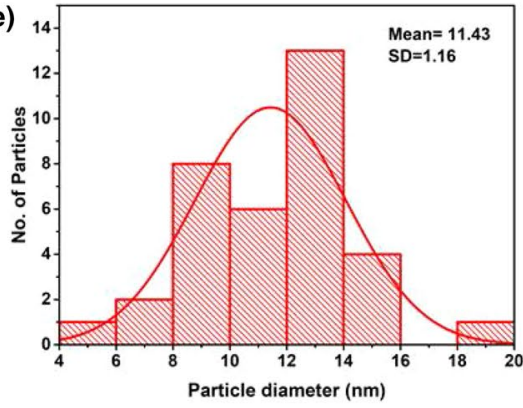

(f)

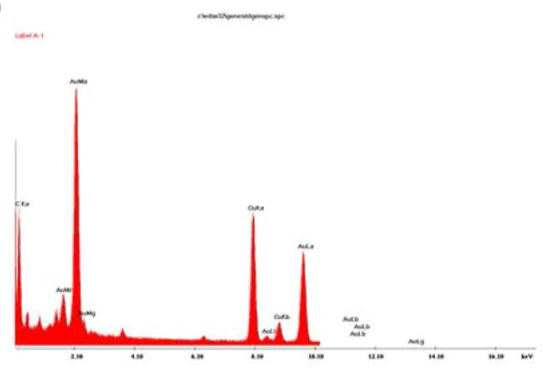

(g)

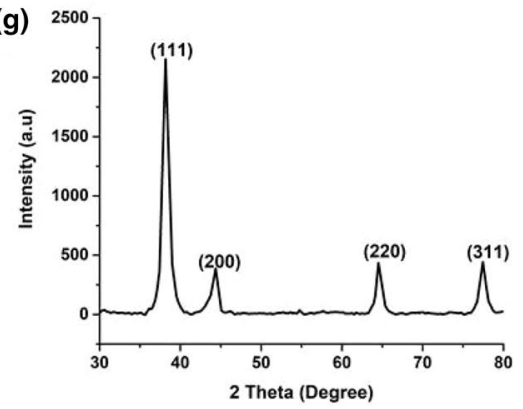

Fig. 6 a-c HR-TEM images of AuNPs at various magnifications d SAED pattern e particle size histogram $\mathbf{f}$ EDAX spectrum and $\mathbf{g}$ XRD pattern of biosynthesized AuNPs under optimum conditions

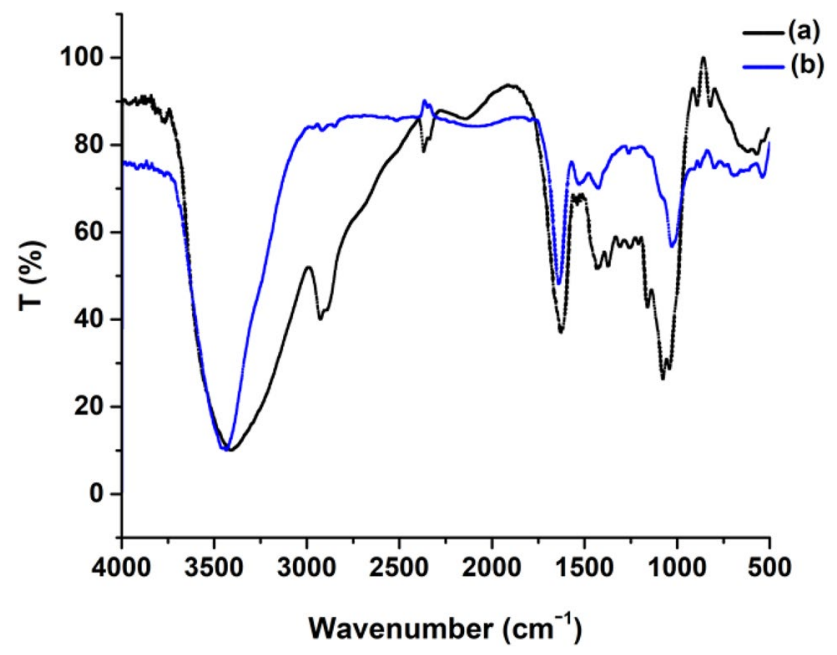

Fig. 7 FTIR spectra of (a) SWE and (b) AuNPs

$11.4 \mathrm{~nm}$ (Fig. 6e).The existence of elemental gold was confirmed from the EDAX profile (Fig. 6f). The high crystallinity of the biogenic AuNPs was established by clear lattice fringes in the HR-TEM image (Fig. 6c) and bright circular spots the in SAED pattern (Fig. 6d) and diffraction peaks corresponding to (111), (200), (220), and (311) lattice planes in XRD profile (Fig. 6g).

The FTIR spectrum of SWE and AuNPs are shown in Fig. 7. It is seen that all major peaks in the SWE were present in the AuNPs displaying the powerful reducing nature and capping effect of the SWE. The broad peak appeared between 3400 and $3450 \mathrm{~cm}^{-1}$ is owing to the of $\mathrm{O}-\mathrm{H}$ stretching vibrations of alcohols and phenols, small peak at $2926 \mathrm{~cm}^{-1}$ is attributed to aliphatic $\mathrm{C}-\mathrm{H}$ stretching, the sharp band at $1640 \mathrm{~cm}^{-1}$ arose from $-\mathrm{C}=\mathrm{O}$ stretching of carbonyl groups of protein, the absorption peak at $1028 \mathrm{~cm}^{-1}$ corresponds to the carboxylic acid functional group [24]. These results suggested that several phytochemical metabolites in SWE might be adsorbed on the surface of AuNPs, and might be accountable for the reduction as well as stabilization of AuNPs. But the exact nature and chemical composition of compounds needs a detailed investigation.

\section{Catalytic efficacy of AuNPs in the reduction of organic dyes}

Because of their exceptional small size and high surface area to volume fraction, metal nanoparticles can act as excellent catalysts. The catalytic potential of AuNPs biosynthesized under optimum conditions was examined for the reduction reactions of Congo red (CR) and eosin yellow (EY) using $\mathrm{NaBH}_{4}$.

Congo red is a non-biodegradable $2^{\circ}$ diazo dye, extensively used in textiles, rubber and paper industries. Due to the toxic nature, its degradation and eradication are very important. In aqueous medium CR is deep red in colour and shows two absorption peaks (Fig. 8a) at 498 and $350 \mathrm{~nm}$ owing to $\pi \rightarrow \pi^{*}$ and $n \rightarrow \pi^{*}$ transitions of the $-\mathrm{N}=\mathrm{N}-$ group, respectively [25]. Catalytic degradation of $\mathrm{CR}$ using $\mathrm{NaBH}_{4}$ yield diphenyl and 4-aminonaphthalene-1-sulfonate [26]. The rate of reduction of $\mathrm{CR}$ by $\mathrm{NaBH}_{4}$ have been studied 
Fig. 8 a The UV-visible absorption spectrum of aqueous solution of $\mathrm{CR} \mathbf{b}$ reduction of CR by $\mathrm{NaBH}_{4}$ without AuNPs c reduction of $\mathrm{CR}$ by $\mathrm{NaBH}_{4}$ using AuNPs d Plot of $\ln \left(A / A_{0}\right)$ verses reaction time in the reduction of CR using AuNPs
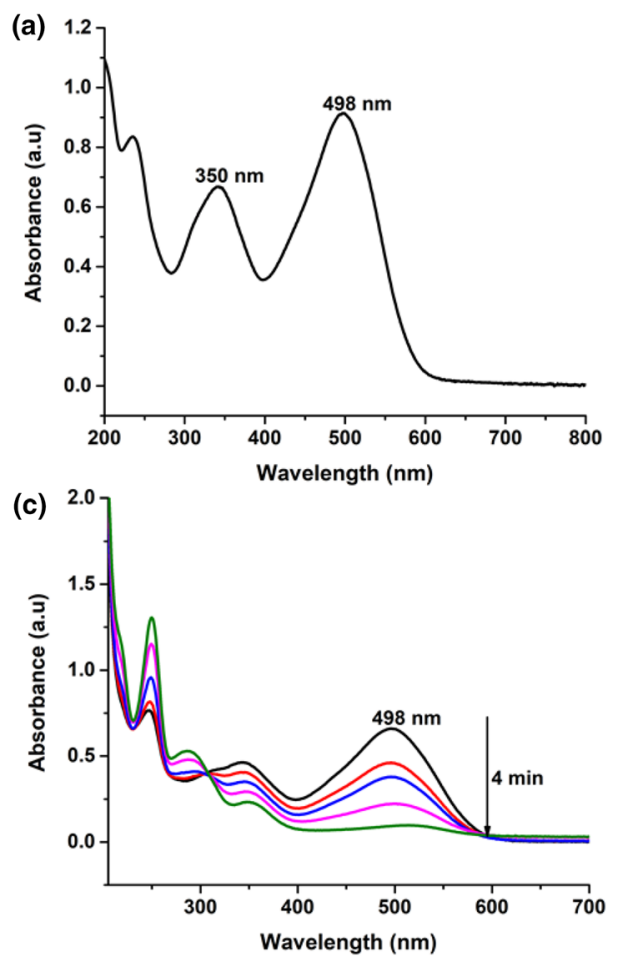

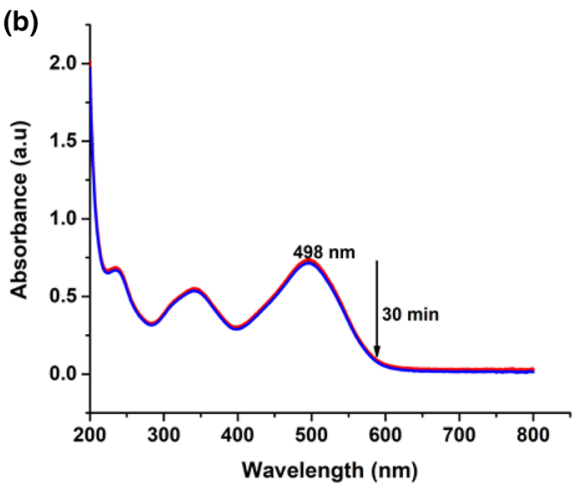

(d)

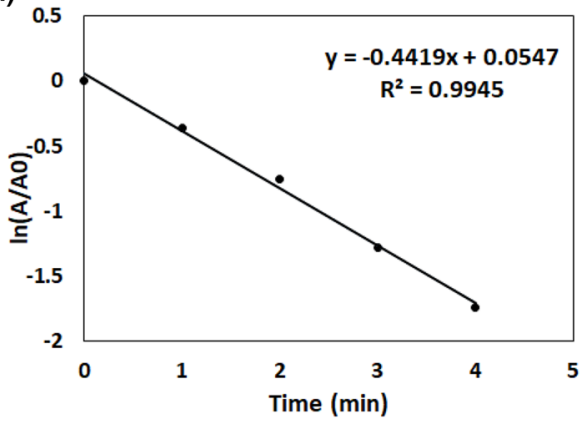

both in presence and absence of AuNPs spectrophotometrically by monitoring the peak at $498 \mathrm{~nm}$. In the absence of nanocatalyst, the peak at $498 \mathrm{~nm}$ remained almost unchanged (Fig. 8b), demonstrating that the reduction of CR by $\mathrm{NaBH}_{4}$ is insignificantly slow owing to the appreciable variance in redox potential between them [27]. Consequently, this reaction is not kinetically favourable without a catalyst and could not be performed simply with the reducing agent $\mathrm{NaBH}_{4}$. However the degradation reaction commenced instantly with the supplement of gold nanocatalyst. This is obvious from the vanishing of red colour of the reaction medium along with a drop in intensity of the peak at $498 \mathrm{~nm}$. The degradation was found to be completed within $4 \mathrm{~min}$ (Fig. 8c).

$\mathrm{EY}$ is a tetrabromofluorescein dye, widely employed in paper, textile and leather industries and forms a major dye pollutant [28]. Orange red coloured solution of EY showed an absorption maxima at $515 \mathrm{~nm}$ (Fig. 9a). The catalytic efficacy of the biosynthesized AuNPs was also assessed for the reduction reaction of $\mathrm{EY}$ by $\mathrm{NaBH}_{4}$. Here also, there is no apprecible change witnessed when the reaction executed without nanocatalyst (Fig. 9b). But reduction occured instantly with the addition of AuNPs and the red colour of the solution gradually turned to colourless. The degradation reaction was accomplished within 6 min as was clear from almost nil absorption at $515 \mathrm{~nm}$ (Fig. 9c).

As the concentration of $\mathrm{NaBH}_{4}$ used as reductant in this study largely exceeds that of dyes, the reaction rate is supposed to be depend only on the concentration of the dye.
For this reason, the rate is assumed to be pseudo first order kinetics and can be denoted as $\ln [C] /\left[C_{0}\right]=-\mathrm{kt}$, where $[C]$ is the concentration of dye at time $\mathrm{t},\left[C_{0}\right]$ is the initial concentration and $\mathrm{k}$ is the pseudo first order rate constant. Since the absorbance is proportional to concentration of solution, the absorbance at time $t(\mathrm{~A})$ and time $0\left(A_{0}\right)$ are comparable to concentration at time $t(C)$ and time $0\left(C_{0}\right)$ [29]. The linear plots of $\ln \left(A / A_{0}\right)$ against time in both the reactions confirmed that the reactions to be in agreement with pseudo first order kinetics (Figs. 8d, 9d). The rate constants of each reaction computed from the slope of the linear plot of $\ln \left(A / A_{0}\right)$ verses reaction time have been detailed in Table 1. The correlation coefficient value for each linear plot is found to be nearly one. The degradation efficiency of the AuNPs for each dye pollutant is also evaluated by calculating the $\%$ degradation and was found to be 92 and $96 \%$ for CR and EY, respectively.

In both the degradation reactions, the AuNPs took the role of an electron transfer mediator between dye and $\mathrm{NaBH}_{4}$ and the catalytic reduction proceeds by an electron relay effect [30]. As soon as the reactants get adsorbed on the surface of the AuNPs, catalytic reaction occurs by the transmission of electron from $\mathrm{BH}_{4}{ }^{-}$to the dye moiety. Thus, in the above catalysed reactions, AuNPs helped in enabling the reduction by decreasing the activation energy of the reaction and hence performed the task of an efficient catalyst [31]. 
Fig. 9 a Spectral data of EY in aqueous solution $\mathbf{b}$ reduction of EY by $\mathrm{NaBH}_{4}$ without AuNPs c catalytic reduction of $\mathrm{EY}$ by $\mathrm{NaBH}_{4}$ using AuNPs d Plot of $\ln \left(A / A_{0}\right)$ verses reaction time for the reduction of EY using gold nanocatalyst
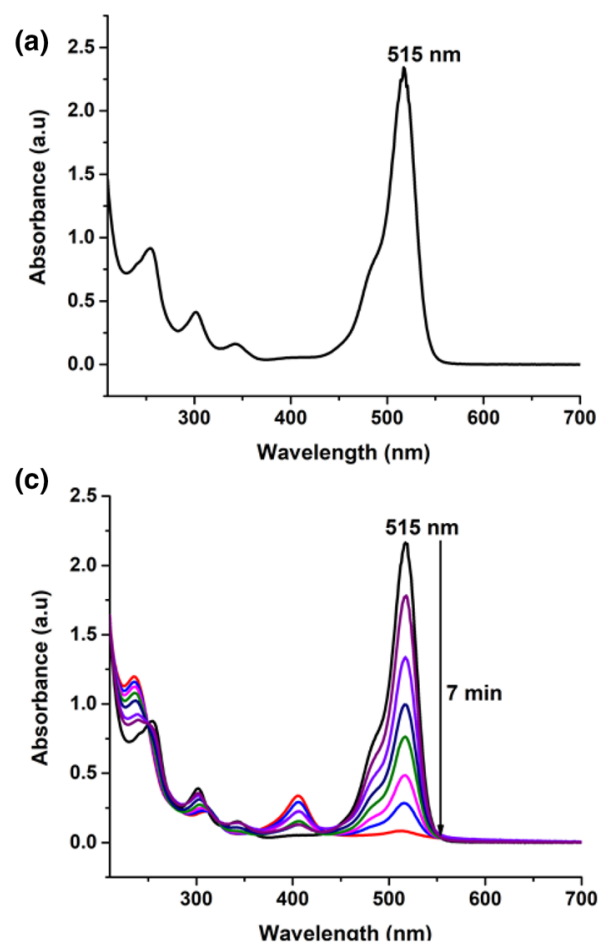

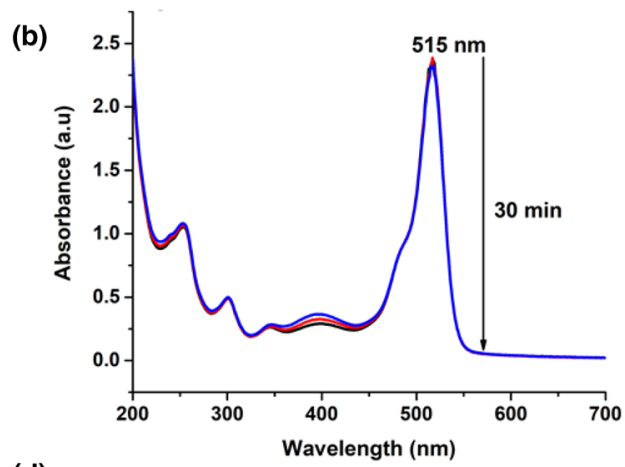

(d)

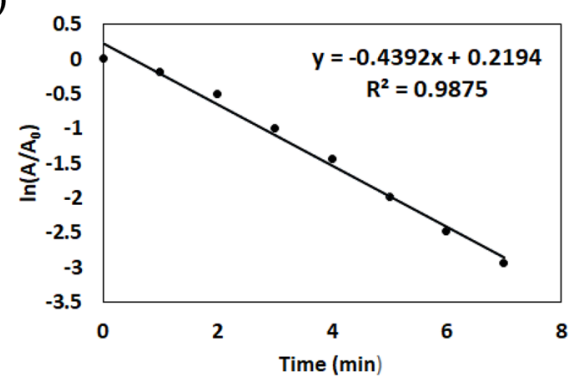

Table 1 Catalytic activity of $100 \mu \mathrm{L}$ AuNPs $(1 \mathrm{mg} / \mathrm{mL})$ in the reduction of dyes

\begin{tabular}{llll}
\hline Dyes & $\begin{array}{l}\text { Reaction time } \\
(\mathrm{min})\end{array}$ & $K\left(\mathrm{~min}^{-1}\right)$ & $\begin{array}{l}\text { Correlation } \\
\text { coefficient } \\
\left(R^{2}\right)\end{array}$ \\
\hline $\mathrm{CR}$ & 4 & 0.4419 & 0.9945 \\
$\mathrm{EY}$ & 7 & 0.4392 & 0.9875 \\
\hline
\end{tabular}

\section{Conclusion}

The present study demonstrated the optimized biosynthesis of highly stable and monodispersed AuNPs by a completely green process by means of aqueous extract of marine macroalgae-Padina tetrastromatica as effective reducing and stabilizing agent. Optimization studies revealed that different physicochemical parameters like the quantity of seaweed extract, temperature, metal ion concentration, $\mathrm{pH}$ and reaction time greatly affected the rate of formation, size and distribution of nanoparticles. On optimizing the synthesis conditions, small, spherical and monodispersed AuNPs were formed, which were characterized by UV-Vis, HR-TEM, SAED, EDAX, XRD and FTIR techniques. Biosynthesized AuNPs under optimum conditions performed as efficient catalyst in the degradation of harmful pollutants Congo red and eosin yellow using $\mathrm{NaBH}_{4}$. These catalytic reduction reactions were very quick and followed pseudo-first order kinetics. Thus, seaweed mediated biosynthesized AuNPs could act as promising materials for the application in environmental protection.

Acknowledgement The authors are pleased to acknowledge STIC, KOCHI, School of Pure and Applied Physics, M.G. University, Kottayam and NIIST, Thiruvananthapuram for characterization studies.

\section{Compliance with ethical standards}

Conflict of interest The authors declare that they have no competing interests.

Open Access This article is distributed under the terms of the Creative Commons Attribution 4.0 International License (http://creativeco mmons.org/licenses/by/4.0/), which permits unrestricted use, distribution, and reproduction in any medium, provided you give appropriate credit to the original author(s) and the source, provide a link to the Creative Commons license, and indicate if changes were made.

\section{References}

1. Zayed, M.F., Eisa, W.H.: Phoenix dactylifera L. leaf extract phytosynthesized gold nanoparticles; controlled synthesis and catalytic activity. Spectrochim. Acta. A. 121, 238-244 (2014)

2. Funston, A.M., Novo, C., Mulvaney, P., Liz-marza, L.M.: Modelling the optical response of gold nanoparticles. Chem. Soc. Rev. 37, 1792-1805 (2008)

3. Segura, R., Pizarro, J., Diaz, K., Placencio, A., Godoy, F., Pino, E.: Development of electrochemical sensors for the determination 
of selenium using gold nanoparticles modified electrodes. Sens. Actuators. B. Chem. 220, 263-269 (2015)

4. Dykmana, L., Khlebtsov, N.: Gold nanoparticles in biomedical applications: recent advances and perspectives. Chem. Soc. Rev. 41, 2256-2282 (2012)

5. Abdul Salam, H., Rajiv, P., Kamaraj, M., Jagadeeswaran, P., Gunalan, S., Rajeshwari, S.: Plants: green route for nanoparticle synthesis. Int. Res. J. Biol. Sci. 1, 85-90 (2012)

6. Joseph, S., Mathew, B.: Microwave assisted facile green synthesis of silver and gold nanocatalysts using the leaf extract of Aerva lanata. Spectrochim. Acta. A. Mol. Biomol. Spectrosc. 136, 1371-1379 (2015)

7. Rajan, A., Vilas, V., Philip, D.: Studies on catalytic, antioxidant, antibacterial and anticancer activities of biogenic gold nanoparticles. J. Mol. Liq. 212, 331-339 (2015)

8. Mata, R., Bhaskaran, A., Sadras, S.R.: Green-synthesized gold nanoparticles from Plumeria alba flower extract to augment catalytic degradation of organic dyes and inhibit bacterial growth. Particuology. 24, 78-86 (2016)

9. Balashanmugam, P., Durai, P., Balakumaran, M.D., Kalaichelvan, P.T.: Phytosynthesized gold nanoparticles from $C$. roxburghii DC. Leaf and their toxic effects on normal and cancer cell lines. J. Photochem. Photobiol. B. Biol. 165, 163-173 (2016)

10. Francis, S., Koshy, E., Mathew, B.: Microwave aided synthesis of silver and gold nanoparticles and their antioxidant. Antimicrob. Catal. Potentials. J. Nanostruct. 8(1), 55-66 (2018)

11. Sujitha, M.V., Kannan, S.: Green synthesis of gold nanoparticles using citrus fruits (Citrus limon, Citrus reticulata and Citrus sinensis) aqueous extract and its characterization. Spectrochim. Acta. A. Mol. Biomol. Spectrosc. 102, 15-23 (2013)

12. Nadeem, M., Abbasi, B.H., Younas, M., Ahmad, W., Khan, T.: A review of the green syntheses and anti-microbial applications of gold nanoparticles. Green. Chem. Lett. Rev. 10(4), 216-227 (2017)

13. Radhakrishna, M., Babu, D.R., Gengan, R.M., Chandra, S., Rao, N.R.: Green synthesis of gold nanoparticles using marine algae and evaluation of their catalytic activity. J. Nanostruct. Chem. 6(1), 1-13 (2016)

14. Arockiya Aarthi Rajathi, F., Parthiban, C., Ganesh Kumar, V., Anantharaman, P.: Biosynthesis of antibacterial gold nanoparticles using brown alga, Stoechospermum marginatum (kützing). Spectrochim. Acta. A. 99, 166-173 (2012)

15. Sethi, P.: Biochemical composition of marine brown algae, Padina tetrastromatica hauck. Int. J. Curr. Pharm. Res. 4, 117-118 (2012)

16. Khalil, M.H., Ismail, E.H., EI-Magdoub, F.: Biosynthesis of $\mathrm{Au}$ nanoparticles using olive leaf extract. Arab. J. Chem. 5, 431-437 (2012)

17. Kannan, R.R.R., Stirk, W.A., Van Staden, J.: Synthesis of silver nanoparticles using the seaweed Codium capitatum P.C. Silva (Chlorophyceae). S. Afr. J. Bot. 86, 1-4 (2013)

18. Gangula, A., Podila, R., Ramakrishna, M., Karanam, L., Janardhana, C., Rao, A.M.: Catalytic reduction of 4-nitrophenol using biogenic gold and silver nanoparticles derived from Breynia rhamnoides. Langmuir. 27, 15268-15274 (2011)

\section{Affiliations}

\section{K. F. Princy ${ }^{1} \cdot$ Anu Gopinath ${ }^{2}$}

Anu Gopinath

anugowri@hotmail.com

1 Department of Chemistry, St. Albert's College, Ernakulam, Kerala, India
19. Mulvaney, P.: Surface plasmon spectroscopy of nanosized metal particles. Langmuir. 12, 788-800 (1996)

20. Rajan, A., Meenakumari, M., Philip, D.: Shape tailored green synthesis and catalytic properties of gold nanocrystals. Spectrochim. Acta. A. 118, 793-799 (2014)

21. Suvith, V.S., Philip, D.: Catalytic degradation of methylene blue using biosynthesized gold and silver nanoparticles. Spectrochim. Acta. A. 118, 526-532 (2014)

22. Ghosh, S., Patil, S., Ahire, M., Kitture, R., Jabgunde, A., Kale, S., Pardesi, K., Bellare, J., Dhavale, D.D., Chopade, B.A.: Synthesis of gold nanoanisotrops using Dioscorea bulbifera tuber extract. J. Nanomater. 2011, 45 (2011). https://doi.org/10.1155/2011/35479 3

23. Armendariz, V., Herrera, I., Peralta-Videa, J.R., Jose-yacaman, M., Troiani, H., Santiago, P., Gardea-Torresdey, J.L.: Size controlled gold nanoparticle formation by Avena sativa biomass: use of plants in nanobiotechnology. J. Nanopart. Res. 6, 377-382 (2004)

24. Song, J.Y., Jang, H.K., Kim, B.S.: Biological synthesis of gold nanoparticles using Magnolia kobus and Diopyros kaki leaf extracts. Process. Biochem. 44, 1133-1138 (2009)

25. Farzaneh, F., Haghshenas, S.: Facile synthesis and characterization of Nanoporous $\mathrm{NiO}$ with folic acid as photodegradation catalyst for Congo red. Mater. Sci. Appl. 3, 697-703 (2012)

26. Rostami-Vartooni, A., Nasrollahzadeh, M., Alizadeh, M.: Green synthesis of perlite supported silver nanoparticles using Hamamelis virginiana leaf extract and investigation of its catalytic activity for the reduction of 4-nitrophenol and Congo red. J. Alloys. Compd. 680, 309-314 (2016)

27. Alle, M., Guttena, V.: Catalytic reduction of methylene blue and Congo red dyes using green synthesized gold nanoparticles capped by Salmalia malabarica gum. Int. NanoLett. 5, 215-222 (2015)

28. Sinha, T., Ahmaruzzaman, M., Bhattacharjee, A., Asif, M., Gupta, V.K.: Lithium dodecyl sulphate assisted synthesis of Ag nanoparticles and its exploitation as a catalyst for the removal of toxic dyes. J. Mol. Liq. 201, 113-123 (2015)

29. Bindhu, M.R., Umadevi, M.: Antibacterial and catalytic activities of green synthesized silver nanoparticles. Spectrochim. Acta. A. 135, 373-378 (2015)

30. Joseph, S., Mathew, B.: Microwave-assisted green synthesis of silver nanoparticles and the study on catalytic activity in the degradation of dyes. J. Mol. Liq. 204, 184-191 (2015)

31. Aromal, S.A., Philip, D.: Green synthesis of gold nanoparticles using Trigonella foenum-graecum and its size-dependent catalytic activity. Spectrochim. Acta. A. 97, 1-5 (2012)

Publisher's Note Springer Nature remains neutral with regard to jurisdictional claims in published maps and institutional affiliations.

2 Department of Fishery Hydrography, Kerala University of Fisheries and Ocean Studies, Cochin, India 